on the turnover rate. On the basis of these experiments Kisilevsky has attempted a generalisation as to the mechanism underlying amyloid deposition. In his view the precursors of amyloid are $l$-chains in myelomaassociated amyloid and $\alpha_{2}$-globulin when the disease is secondary to an inflammatory state.

In such conditions an increased load of glycoproteins, which will be accounted for largely by the increased concentrations of SAA, will be taken up by the reticuloendothelial system (RES). If the RES is overloaded or functioning less than optimally, as for instance after treatment with BCG, degradation of $\alpha_{2}$ globulins, and in particular SAA, will not go to completion. Thus, subunits will then accumulate and in due course will combine to form fibrils. However, for this to happen certain additional conditions are likely to be necessary. Since the partial breakdown of the SAA protein or other glycoproteins will occur in the lysosomes differences in respect to lysosomal enzymes are likely to be important. The existence of genetic differences in respect to amyloidosis has already been mentioned. Minor genetically-determined structural differences may perhaps be responsible for the enhanced tendency to associate as amyloid fibrils shown by the SAA obtained from amyloid plasma.

\section{Anoxic events in the Cretaceous ocean}

\section{from A. Hallam}

That the Black Sea is stagnant in its deeper part is a widely known and comparatively well understood fact. Freshwater runoff from the surrounding land promotes salinity and hence density layering which is not destroyed by convective overturn because of restriction on interchange with Mediterranean waters by the sill of the Bosphorus. The surface waters contain free oxygen because of photosynthetic activity and exchange with the atmosphere, but at greater depth an anaerobic condition is produced as oxygen is consumed by organisms and replaced by hydrogen sulphide, the by-product of the metabolic activity of sulphate-reducing bacteria. In consequence the bottom sediments are rich in unoxidised bituminous matter derived both from terrestrial plants and phytoplankton, together with iron sul-

A. Hallam is Professor of Geology in the University of Birmingham.

\title{
Terminal redundancy in avian oncornavirus RNA
}

\section{from T. J. R. Harris}

THE avian oncornaviruses provide a good model for analysing the modus operandi of the Retroviridae. Viruses in this family make a DNA copy of their single stranded genome RNA using the RNA-dependent DNA polymerase (reverse transcriptase) packaged in the virus particle. This complementary DNA (cDNA) is then copied into a circular double-stranded DNA molecule which can integrate into the host cell DNA. Studies in vitro with reverse transcriptase are now beginning to unravel the possible molecular mechanisms behind this interesting sequence of events and to explain how the circular DNA molecules might be formed.

The primer required by reverse transcriptase for the initiation of synthesis is one of the host cell transfer RNA molecules associated with the genome RNA and making up the $70 \mathrm{~S}$ complex in the virus. For both Rous sarcoma virus (RSV) and avian myeloblastosis virus (AMV), the tRNA specific for tryptophan is the one used. As cDNA synthesis proceeds in a $5^{\prime}-3^{\prime}$ direction one might expect that the primer would be bound at the $3^{\prime}$ end of the RNA. Surprisingly, however, Taylor \& Illmensee in a concise paper (J. Virol. 16, 553; 1975) showed for RSV RNA that the primer was in fact bound near the $5^{\prime}$ end of the RNA-a finding since confirmed for AMV RNA (Stakus et al. Virology 71, 162; 1976). Collett \& Faras (Proc. natn. Acad. Sci. U.S.A. 73, 1329; 1976) analysed the cDNA produced by the AMV enzyme and found that molecules containing sequences complementary to the $5^{\prime}$ end of the virus RNA also contained sequences complementary to the $3^{\prime}$ end. These observations led the authors to suggest that some of the sequence at the $5^{\prime}$ end of the virus RNA was repeated at the $3^{\prime}$ end providing both virus RNA and CDNA with the capacity to form circles. Direct evidence has now been obtained from sequencing studies to support this suggestion. Haseltine, Gilbent \& Maxam (Proc. natn. Acad. Sci. U.S.A. 74, 989; 1977) have

phide. They are also finely laminated because no benthonic organisms can survive in the anoxic environment and the sediment is not churned over by burrowers. Because of the name by which the Black Sea was known in the classical world, such sediments and environments are known as euxinic, sequenced the 101 nucleotides of tRNA ${ }^{\text {Trp}}$-primed cDNA complementary to the $5^{\prime}$ end of the virus RNA using their rapid DNA sequencing technique, while Schwartz, Zamecnik \& Weith (Proc. natn. Acad. Sci. U.S.A. 74, 989; 1977) used oligo(dT)primed reverse transcription followed by partial exonuclease digestion of the product to obtain a shont sequence adjacent to the poly (A) at the $3^{\prime}$ end of the virus RNA. The first 21 nucleotides of RSV RNA after the capping group were found to be identical to the 21 before the poly(A). Haseltine et al. discuss in detail the implications of the terminal redundancy for circle formation and formation of provirus DNA and some evidence for the circular structures they envisage is accumulating from heteroduplex analysis of RNA/CDNA hybrids (see Junghans et al. Proc. natn. Acad. Sci. U.S.A. 74, 477; 1977). Also, knowledge of the $5^{\prime}$ cDNA sequence enabled Haseltine et al. to construct plausible models of the possible ways that the $5^{\prime}$ ends of the two genome RNA molecules and their tRNA primers might be associated in the virus particle as the 70 S complex.

The advent of the fast and accurate nucleic acid sequencing methods should enable more of the cDNA sequence to be determined (as well as that of the dsDNA and its precursor molecules) so that some of these speculations can be tested. One must add the proviso however that any mechanism of synthesis outlined from in vitro studies may not necessarily be the same as that actually occurring in vivo. Nevertheless, sequencing the parts of the RNA (by way of cDNA) coding for the structural and non-structural polypeptides will inevitably lead to a greater understanding of the replication of this important family of oncogenic viruses.

T. J. R. Harris is a member of the Bio chemistry Department of the Animal Virus Research Institute, Pirbright, Surrey.

and a Black Sea-type 'barred basin' model has been widely applied by geologists to account for the formation of finely laminated marine bituminous shales.

In marked contrast to the rather unusual Black Sea situation, the floor of the open ocean is well oxygenated, 